\title{
Can Ants Apply What They Acquired Through Operant Conditioning?
}

\author{
Marie-Claire Cammaerts ${ }^{1} \&$ Roger Cammaerts ${ }^{2}$ \\ ${ }^{1}$ Independent researcher, retired from the Biology of Organisms Department, University of Brussels, Belgium \\ ${ }^{2}$ Independent researcher, retired from the Natural and Agricultural Environmental Studies Department (DEMNA) \\ of the Walloon Region, Belgium \\ Corresponding author: Marie-Claire Cammaerts, independent researcher, 27, Square du Castel Fleuri, 1170 \\ Bruxelles, Belgium. Tel: 32-2673-4969. E-mail: mtricot@ulb.ac.be; mccammaerts@gmail.com
}

Received: July 9, 2018

Accepted: July 24, 2018

Online Published: July 31, 2018

doi:10.5539/ijb.v10n4p16

URL: https://doi.org/10.5539/ijb.v10n4p16

\begin{abstract}
Can an act learned through conditioning be adequately presented in a subsequent different situation under which it may be useful to the individuals? We approached this question, working on ants, and staying at a level basic compared to the largely developed Applied Behavior Analysis (ABA) discipline. We simply conditioned the ants of both colonies A and B to a green hollow cube (= the conditioned stimulus CS1) associated with sugar water (= the unconditioned stimulus US1), and to basilica (= the conditioned stimulus CS2) associated with meat (= the unconditioned stimulus US2). We then deprived colony A of sugar water and colony B of meat. Thereafter, when confronted to the two conditioned stimuli at the same time, the ants of colony A chose CS 1 (previously associated with sugar water), and the ants of colony B chose the CS 2 (previously associated with meat). The ants chose thus the CS corresponding to the US of which they were deprived. They applied thus a behavior learned through conditioning in a subsequent situation under which this behavior may be useful. During our test experiment, the ants strongly responded to the adequate CS due to their high motivation resulting from starvation. Conditioning techniques might also be usefully used during humans' treatment under the ABA discipline. Increasing the patients' motivation during some conditioning performed for caring them may enhance the impact of that conditioning on the treatment efficiency.
\end{abstract}

Keywords: applied behavior analysis, conditioned and unconditioned stimuli, cognition, Myrmica sabuleti, use of knowledge

\section{Introduction}

Working on ants since 1969, we progressively tried to define their cognitive abilities and the limits of these abilities. We recently showed that these insects can memorize a behavioral sequence and acquire serial recognition, but only if rewarded while being trained to the sequence or the ordered series of elements to memorize (Cammaerts \& Cammaerts, $2018 \mathrm{a}, \mathrm{b}, \mathrm{c})$. Pursuing our goal, we examined if ants could present a behavior acquired through operant conditioning, when experiencing a new situation under which that behavior should be advantageously exhibited. In other words, could ants apply, in a novel situation, a behavior previously acquired through conditioning? Though it was not our initial aim, our new ethological research project, i.e. the ants' ability in applying subsequently a reaction acquired under other circumstances through conditioning, joins a scientific discipline firstly named 'behavior modification' and presently named 'Applied Behavior Analysis (ABA)' (https://en.wikipedia.org/wiki/Applied_behavior_analysis). ABA is not exclusively an analysis of behavior; it also develops procedures which will produce changes in behavior in accordance with potential environmental changes. ABA is thus a very broad ethological field dealing with individuals' applied forms of behavior in relation with the environment. ABA concerns therefore a wide range of areas, behaviors and behavioral problems such as early intensive behavioral interventions for children with an autism spectrum disorder (ASD), research on the principles influencing criminal behavior, education, severe mental disorders, substance abuse, phobias, zoo management and care of animals (Baer, Wolf, \& Risley, 1968, 1987; Powers, Osborne, \& Anderson, 1973; Kuhm, Lerman, \& Vorndran, 2003; Mayer, Sulzer-Azaroff, \& Wallace, 2011).

In the present work on ants, we stayed at a simple basic level in comparison with that of the largely developed ethological discipline ABA. We only researched if ants can use something learned (i.e. acquired by conditioning) later on, in a novel situation. We imagined a simple experiment consisting in: 1) conditioning the ants of two 
colonies to two different stimuli (two conditioned stimuli, CS), one associated with one kind of unconditioned stimuli (US1 = sugar water), the other with another kind of unconditioned stimuli (US2 = meat); 2 ) then depriving one colony of sugar water and the other one of meat; 3 ) and finally testing, separately, the ants of the two colonies in front of the two different CS. Will they present a preference for the CS previously associated with the US of which they have been deprived? Such an experiment is simple and basic, compared to the handlings made under the label 'ABA', but it is an elegant experiment dealing with an adequate use of a behavior acquired by conditioning, and an experimental research never performed in this way on insects, even if some works approached doing so (Cammaerts \& Rachidi, 2009; Cammaerts, Rachidi, Beke \& Essaadi, 2012; Cammaerts, 2012; Cartwright \& Collett, 1983).

\section{Material and Methods}

\subsection{Collection and Maintenance of Ants}

The experiments were made on two colonies of M. sabuleti collected at Rédange (France, Moselle department) in May 2017. They contained about 500 workers, brood and one queen. Each colony was maintained in glass tubes half filled with water, a cotton plug separating the ants from the water. For each colony, these tubes were deposited in a tray $(34 \mathrm{~cm} \times 23 \mathrm{~cm} \times 4 \mathrm{~cm})$, the borders of which were covered with talc to avoid ants' escaping (Figure 2A). The ants were fed with an aqueous solution of sugar given ad libidum in a small tube plugged with cotton, and with cut Tenebrio molitor larvae (Linnaeus, 1758) given as necessary. The air temperature equaled $20-21^{\circ} \mathrm{C}$, the humidity about $80 \%$, the intensity of lighting 330 lux while working on ants and $5-120$ lux during other time periods, and the electromagnetic field equaled $2-3 \mu \mathrm{W} / \mathrm{m}^{2}$. These laboratory parameters were optimum for the species. The workers are here often named nestmates, as do researchers on social insects.

\subsection{Training the Ants}

The ants of the two colonies were collectively visually trained to a hollow green cube (conditioned stimuli 1: CS1) constructed of strong paper (Canson ${ }^{\circledR}$ ) according to the instructions given in Cammaerts and Nemeghaire (2012) and set over the entrance of the sugar water tube (the unconditioned stimuli 1: US1). At the same time (the start of the conditioning being exactly the same), the ants of the two colonies were olfactory conditioned to pieces of basilica (the CS2) set aside the pieces of T. molitor larvae, i.e. meat food (the US2). Note that the color of the green cube has been analyzed to determine its wavelengths reflection (Cammaerts, 2007), and that only the ceiling of the cubes was filled, this allowing ants entering the cube.

After that, the ants of the two colonies were tested in the course of time in order to check if they effectively acquired visual and olfactory conditioning, and to know exactly when they reached their optimum score of conditioning. They were tested successively in two Y-apparatus (see below in this paragraph) constructed of strong white paper according to the instructions given in Cammaerts et al. (2011), and set in a small tray (30 cm x $15 \mathrm{~cm} \times 4 \mathrm{~cm}$ ), apart from the experimental colony's tray. Each colony had its own testing device. The Y-apparatus had their own bottom and their sides were slightly covered with talc to prevent the ants from escaping. In the Y-apparatus, the ants deposited no trail since they were not rewarded. However, they could utilize other chemical secretions as traces. As a precaution, the floor of each Y-apparatus was changed between tests. One of the $\mathrm{Y}$-apparatus was provided with a green cube, the other one with pieces of basilica, in one or the other of their branches (Figure 2A). Half of the tests were conducted with the cube or the odorous plant in the left branch of the $\mathrm{Y}$-apparatus and the other half with the cube or the odorous plant in the right branch, and this was randomly chosen. Choosing the branch containing the green cube, or the basilica, was considered as giving the 'correct' choice. Before setting the green cube and the basilica on the sugar water tube entrance and aside the pieces of $T$. molitor respectively, a test was made (at $\mathrm{t}=0$ ) in the two $\mathrm{Y}$-apparatus, the results serving as controls.

To conduct a test on a colony, 10 workers - randomly chosen from the workers of that colony - were transferred one by one onto the area at the entrance of the Y-apparatus. Each transferred ant was observed until it turned either to the left or to the right in the Y-tube, and its choice was recorded. Only the first choice of the ant was recorded and this only when the ant was entirely under the cube or aside the basilica, i.e. beyond a pencil drawn thin line indicating the entrance of a branch (Figure 2B, C). Afterwards, the ant was removed and transferred into a polyacetate cup, the border of which was covered with talc, until 10 ants were so tested, this avoiding testing the same ant twice. All the tested ants were then placed back on their foraging area. For each test, the numbers of ants, among $\mathrm{n}=10+10=20$ which turned towards the "correct" green cube or pieces of basilica, or went to the "wrong" branch of the $\mathrm{Y}$ were recorded. The percentage of correct responses for the tested ant population was established (Table 1). Testing the ants ended when the ants' scores no longer increased. 
Table 1. Ants' acquisition of olfactory and visual conditioning.

\begin{tabular}{ccccccccr}
\hline \multirow{2}{*}{ Time (hours) } & \multicolumn{3}{c}{ Olfactory conditioning } & & \multicolumn{3}{c}{ Visual conditioning } \\
\cline { 2 - 3 } \cline { 7 - 8 } \cline { 6 - 8 } & colony A & Colony B & $\%$ & & colony A & Colony B & $\%$ \\
\hline 0 & 5 & 5 & $50 \%$ & & 5 & 5 & $50 \%$ \\
24 & 7 & 8 & $75 \%$ & & 7 & 8 & $75 \%$ \\
48 & 9 & 8 & $85 \%$ & & 8 & 8 & $80 \%$ \\
72 & 9 & 9 & $90 \%$ & & 9 & 8 & $85 \%$ \\
96 & 9 & 9 & $90 \%$ & & 8 & 9 & $85 \%$ \\
\hline
\end{tabular}

The table gives the number of ants out of 10 choosing the correct branch of the Y-apparatus. Ants obviously acquired olfactory and visual conditioning, reaching an optimum score of $90 \%$ and $85 \%$ respectively after 72 training hours.

\section{Training to basilica (US = meat) and green cube (US = sugar water) \\ + Checking the ants' acquisition of conditioning thanks to tests in Y-apparatus}
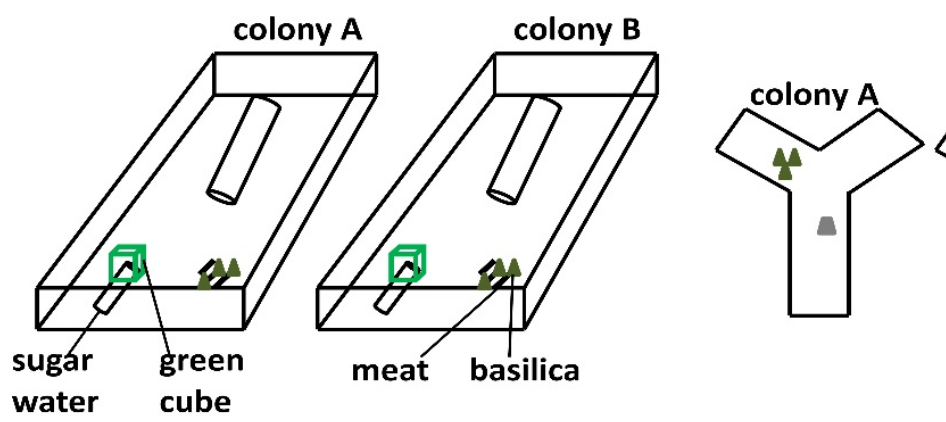

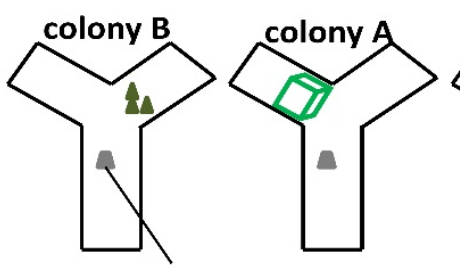

experimented ant

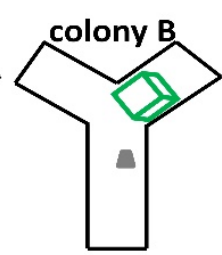

2. Starving: colony A deprived of sugar water ; colony B deprived of meat

\section{Testing}

\section{After 1 day, ants of colony $A$}

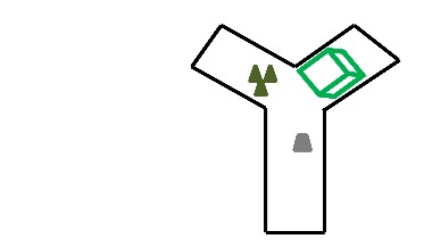

should move to the green cube

\section{Expected:}

After 2 days, ants of colony B

\section{if applying their conditioning}

Figure 1. Experimental protocol.

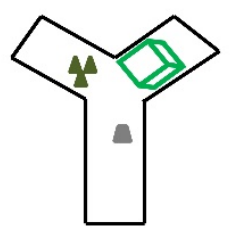

should move to basilica

Ants of two colonies (A, B) were conditioned to a green cube (the unconditioned stimulus (US) being sugar water), and to basilica (the unconditioned stimulus being meat). After the ants acquired such conditioning, colony $\mathrm{A}$ was deprived of sugar water, and colony B of meat. After 1 and 2 days respectively, they were tested in front of the two conditioned stimuli (green cube and basilica). If applying their acquired conditioning, ants of colony A deprived of sugar water should chose the green cube, and ants of colony B deprived of meat should chose the basilica. 

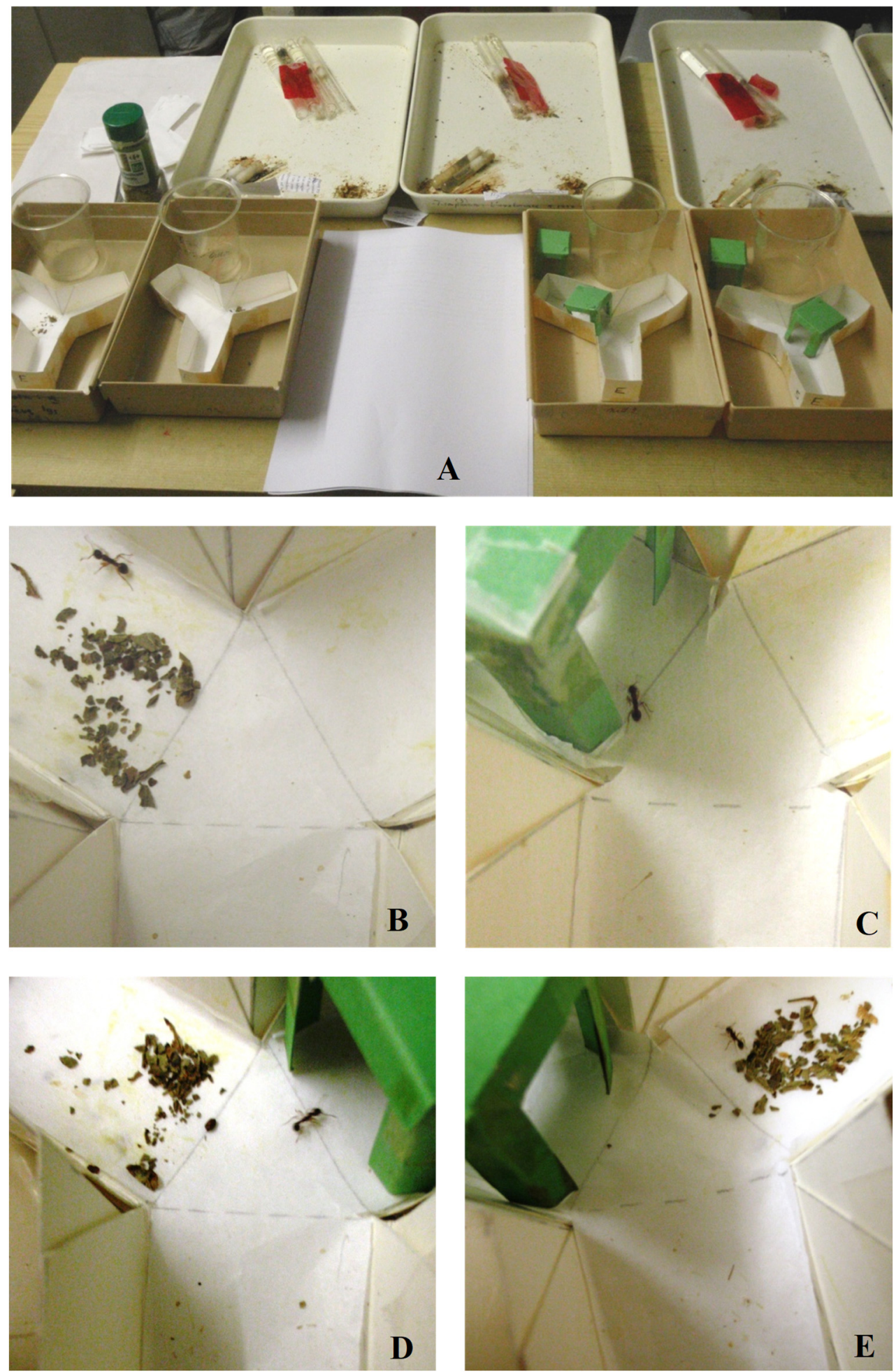

Figure 2. Some views of the experimental work

A: the entire experimental design, just before starting the work. B: an ant trained to basilica (and to a green hollow cube) giving the correct response when tested in a Y-apparatus provided with that olfactory cue in the left branch. C: an ant trained to a green hollow cube (and to basilica) giving the correct response when tested in a Y-apparatus provided with that visual cue in the left branch. D: an ant deprived of sugar water since one day, tested in a Y-apparatus provided with the two conditioned stimuli, and moving promptly to the green hollow cube associated to sugar water during training. $\mathbf{E}$ : an ant deprived of meat since two days, tested in a Y-apparatus provided with the two conditioned stimuli, and having promptly moved to basilica associated with meat during training. 


\subsection{Starving the Ants}

Just after having performed the last test for checking the ants' conditioning acquisition, deprival of sugar water started for colony A (but the small tube and the green cube stayed in place, and the cotton plug of the small tube was not refreshed), and colony B was deprived of pieces of $T$. molitor (but the old, empty pieces of meat and their support, as well as the pieces of basilica stayed in place). Doing so, after a few hours, the ants of colony A were lacking of sugar water, while about after one day, the ants of colony B were lacking of meat. Consequently, the ants of colony A were tested twice one day after their sugar deprivation, and the ants of colony B were tested twice two days after their meat deprivation (see below).

\subsection{Testing the Ants}

After having been deprived of sugar water during one day (see above), 20 ants of colony A were tested twice during the same day in a Y-apparatus provided with a green cube in one of its branch, and with pieces of basilica in its other branch (Figure 2D). The ants' choice between these two CS was recorded in the course of the two tests (Table 2). After having been deprived of meat during two days (see above), 20 ants of colony B were tested twice during the same day in a Y-apparatus provided with a green cube in one of its branch and with pieces of basilica in its other branch (Figure 2E). The ants' choice between these two CS was each time recorded (Table 2). For each two colonies, the numbers of ants choosing each kind of CS were compared to those expected if ants randomly chose them, using the non-parametric $\chi^{2}$ test (Siegel \& Castellan, 1989).

\section{Results}

\subsection{Training the Ants to two Conditioned Stimuli}

Before being conditioned, the ants randomly navigated the $\mathrm{Y}$-apparatus provided with either the olfactory or the visual cue in one of its branch (Table 1, line 1: 50\%, 50\%). The ants of the two colonies perfectly acquired olfactory as well as visual conditioning (Table 1, Figure $2 \mathrm{~B}, \mathrm{C}$ ). After 24, 48 and finally 72 training hours, the ants responded to the olfactory cue with a score of $90 \%$ and to the visual cue with a score of $85 \%$. After a total of 96 training hours, the ants' olfactory and visual conditioning scores no longer increased (Table 1), and the experimental work could thus go on. This means that colony A was deprived of sugar water for one day, and colony B of meat for two days, and that, after these time periods, the ants were tested in front of the two conditioned stimuli (see the following paragraph)

Table 2. Responses of ants, out of 20, deprived of the US sugar water (colony A) or of the US meat (colony B), to the CS associated with these two US, i.e. respectively a green cube and basilica

\begin{tabular}{lcccccc}
\hline \multirow{2}{*}{ Experiments } & \multicolumn{2}{c}{$\mathrm{N}^{\circ}$ of ants of colony A moving to } & & \multicolumn{2}{c}{$\mathrm{N}^{\circ}$ of ants of colony B moving to } \\
\cline { 2 - 3 } \cline { 5 - 6 } & The green cube & Basilica & & The green cube & Basilica \\
\hline First test & 17 & 3 & & 3 & 1 & 17 \\
Second test & 18 & 2 & & 1 & \\
\hline
\end{tabular}

Ants of colony A went promptly towards the green cube associated during training with sugar water (of which the ants were deprived for one day), and ants of colony B went promptly towards the basilica associated during training with meat (of which these ants were deprived for two days). Ants presented thus a behavior learned during operant conditioning for responding, later on, in agreement with a novel situation, i.e. their food deprivation.

\subsection{Testing the Ants Deprived of One or the Other Previously Used Unconditioned Stimuli}

The obtained results were qualitatively rather expected, but they were quantitatively really unexpected, the ants reacting more promptly than during their initial conditioning. Indeed, the tested ants responded very quickly, nearly all of them choosing the conditioned stimuli previously associated with the unconditioned stimuli of which they were deprived (Table 2, Figure 2D, E). In details, the ants of colony A deprived of sugar water moved to (or more precisely ran towards) the green hollow cube previously set above the ants' sugar water, doing so with a score of $85 \%$ and $90 \%$ during the first and the second tests respectively. The numerical results obtained (sum of the two tests: 35,5$)$ statistically differed from the random expected ones $\left(20,20 ; \chi^{2}=11.40, \mathrm{df}=1, \mathrm{P}<0.001\right)$. The ants of colony B deprived of meat quickly walked to the basilica previously set aside the ants' meat, reaching a score of $85 \%$ and $95 \%$ during the first and the second tests respectively. The numerical results obtained (sum of the two tests: 36,4$)$ statistically differed from the random expected ones $\left(20,20 ; \chi^{2}=13.39\right.$, df $=1, \mathrm{P}<0.001)$. 


\section{Discussion}

Our work showed that ants could adequately use a response acquired through operant conditioning, later on, in another situation under which the acquired reaction could be useful. This should be confirmed by investigation on other animal species. It should also be examined if such an event is also true for innate acts.

As a matter of fact, Pavlovian (= classical) conditioning allows individuals to "learn" many things, what can later guide their behavior through several reflex-like responses. It may also modulate the vigor of some reflex-like responses (Pearce, 2008, pp 60-61). The latter idea is also valid for operant conditioning, though this procedure is physiologically more complex (Pearce, 2008; Miltenberger, 2008).

In our work, during the testing of ants deprived either of sugar water or of meat, we observed a strong response. This unusual timeliness of response is very probably due to an increase of the ants' motivation resulting from their starvation. Indeed, Pearce (2008, p. 111) and Balleine (2001) underline the importance of the influence of motivational processes on instrumental (= operant) behavior.

Using classical or operant conditioning during humans' or animals' treatment under the ABA discipline (see the introduction section) may be a useful method, i.e. it may help caring of these individuals. It should also be of interest to try increasing the patients (humans or animals)' motivation, e.g. by using highly appreciated rewards, or rewards no longer available since a long time, for improving the impact of the conditioning on the treatment, and enhancing so the occurrence of an expected change of behavior.

\section{References}

Baer, D. M., Wolf, M. M., \& Risley, T. R. (1968). Some current dimensions of applied behavior analysis. Journal of Applied Behavior Analysis, 1(1), 91-97. https://doi.org/10.1901/jaba.1968.1-91

Baer, D. M., Wolf, M. M., \& Risley, T. R. (1987). Some still-current dimensions of applied behavior analysis. Journal of Applied Behavior Analysis, 20(4), 313-327. https://doi.org/10.1901/jaba.1987.20-313

Balleine, B. W. (2001). Incentive processes in instrumental conditioning. In R. R. Mower, \& S. B. Klein (Eds.), Handbook of contemporary learning theories (pp. 307-366). Mahwah, NJ, K Lawrence Erlbaum Associates, Inc. https://books.google.be/books?isbn=0262018098

Cammaerts, M.-C. (2007). Colour vision in the ant Myrmica sabuleti MEINERT, 1861 (Hymenoptera: Formicidae). Myrmecological News, 10, 41-50. Retrieved from https://myrmecologicalnews.org > ... > Volume 10 (2007)

Cammaerts, M.-C. (2012). Navigation system of the ant Myrmica rubra (Hymenoptera, Formicidae). Myrmecological News, 16, 111-121. Retrieved from https://myrmecologicalnews.org > ... > Volume 16 (2012)

Cammaerts, M.-C., \& Cammaerts, R. (2018a). Learning a behavioral sequence: an accessible challenge for Myrmica sabuleti workers? International Journal of Biology, 10(2). https://doi.org/10.5539/ijb.v10n2p1

Cammaerts, M.-C., \& Cammaerts, R. (2018b). Ants can acquire some serial recognition. International Journal of Biology, 10(2), 23-32. https://doi.org/10.5539/ijb.v10n2p31

Cammaerts, M.-C., \& Cammaerts, R. (2018c). Myrmica sabuleti workers cannot acquire serial recognition if not rewarded. International Journal of Biology, 10(3), 39-46. https://doi.org/10.5539/ijb.v10n3p38

Cammaerts, M.-C., \& Nemeghaire, S. (2012). Why do workers of Myrmica ruginodis (Hymenoptera, Formicidae) navigate by relying mainly on their vision? Bulletin de la Société Royale Belge d'Entomologie, 148, 42-52. Retrieved from www.srbe-kbve.be/cm/publications-publicaties

Cammaerts, M.-C., \& Rachidi, Z. (2009). Olfactive conditioning and use of visual and odorous elements for movement in the ant Myrmica sabuleti (Hymenoptera, Formicidae). Myrmecological News, 12, 117-127. Retrieved from https://myrmecologicalnews.org > ... > Volume 12 (2009)

Cammaerts, M.-C., Rachidi, Z., Beke, S., \& Essaadi, Y. (2012). Use of olfactory and visual cues for traveling by the ant Myrmica ruginodis (Hymenoptera, Formicidae). Myrmecological News, 16, 45-55. Retrieved from https://myrmecologicalnews.org > ... > Volume 16 (2012)

Cartwright, B. A., \& Collett, T. S. (1983). Landmark learning in bees: Experiments and models. Journal of Comparative Physiology A, 151, 521-543. https://doi.org/10.1007/BF00605469

Kuhn, S.A.C., Lerman, D.C., \& Vorndran, C.M. (2003). Pyramidal training for families of children with problem behavior. Journal of Applied Behavior Analysis, 36(1), 77-88. https://doi.org/10.1901/jaba.2003.36-77

Mayer, G. R, Sulzer-Azaroff, B., \& Wallace, M. (2011). Behavior Analysis for Lasting Change (2nd Ed.). Sloan. Retrieved from https://www.amazon.com/Behavior-Analysis-Lasting-Change-May... 
Miltenberger, R. G. (2008). Behavioral Modification: Principles and Procedures. Thomson/Wadsworth, p. 104. Retrieved from https://trove.nla.gov.au/work/13951603

Pearce, J. M. (2008). Animal learning and cognition, an introduction. East Sussex: Psychology Press. Retrieved from http://www.worldcat.org/title/animal-learning-cognition-an-introduction/oclc/682223995

Powers, R. B., Osborne, J. G., \& Anderson, E. G. (1973). Positive reinforcement of litter removal in the natural environment. Journal of Applied Behavior Analysis, 6(4), 579-86. https://doi.org/10.1901/jaba.1973.6-579

Siegel, S., \& Castellan, N. J. (1989). Nonparametric statistics for the behavioural sciences. Singapore, McGraw-Hill Book Company. Retrieved from https://www.amazon.com/Sidney-Siegel...Statistics.../B008WDIR6

\section{Copyrights}

Copyright for this article is retained by the author(s), with first publication rights granted to the journal.

This is an open-access article distributed under the terms and conditions of the Creative Commons Attribution license (http://creativecommons.org/licenses/by/4.0/). 